\title{
COMMUNITY SERVICE PROJECTS FOR ASCE STUDENT CHAPTERS
}

\author{
Mark D. Evans and Denise M. Evans \\ United States Military Academy, West Point, NY
}

\section{Introduction}

Community service projects allow chapter members to serve the community, develop leadership skills, interact with professional civil engineers, and hone their own engineering skills on realworld projects. Students perform the role of consultant, corporate president, fund-raiser, project manager, designer, draftsperson, and construction worker. Community service gives students the opportunity to practice their civil engineering skills outside the classroom in "real life" environments. Involved students will acquire more project management experience working on these projects than can be learned in any classroom. Participants are called upon to explore his or her abilities and talents and to communicate ideas logically. Students who can motivate volunteers from start to finish have had a rare opportunity to develop important leadership skills. Chapter members involved in community service cultivate a deep-rooted sense of commitment, not just to the chapter and its members, but also to the community. The "esprit de corps" that results within the chapter is long lasting and is extremely attractive to other students who then want to participate; consequently, the success of the chapter becomes self-fulfilling. Community service projects are key activities for ASCE student chapters, contributing greatly to the education of civil engineering students who participate actively ${ }^{1,2,3}$. In this paper, the student chapter advisor, chapter leaders, and members will learn proven strategies for conceiving, organizing, and running successful student chapter-lead community service projects.

\section{Value of Community Service}

The objectives of a successful ASCE Student chapter are successfully reached through the undertaking of community service projects ${ }^{4,5}$. Community service gives students the opportunity to practice their civil engineering skills outside the classroom in a "real life" environment. Student members should voluntarily accept responsibility for seeing these projects through from beginning to end without receiving any academic credit. Each person can strengthen his or her ability to evaluate situations and set priorities since there often is no entirely right or entirely wrong solution to problems concerning clients, peers, time management, and construction methods. The students will acquire more project management experience working on these projects than can be learned in a classroom. Each participant is called upon to explore his or her abilities and talents and to communicate ideas logically. Most importantly, chapter members involved in community service cultivate a deep-rooted sense of commitment, not just to the Chapter and its members, but also to the community.

The benefits to both the individual members and to the Chapter are enormous. Few activities are so effective in helping students develop leadership skills as the community service project. Students perform the role of consultant, corporate president, fund-raiser, project manager, 
designer, draftsperson, and construction worker. Students soon realize that the most difficult job is holding the project together to the very end. Those students, who can continue to motivate volunteers from start to finish, have had a rare opportunity to develop leadership skills ${ }^{6,7,8,9,10}$. Finally, the self-respect, self-confidence, and sense of satisfaction that is acquired by the students involved in the project are unfathomable. The "esprit de corps" that results within the Chapter is long lasting and is extremely attractive to other students who then want to participate; consequently, the success of the Chapter becomes self-fulfilling.

Good ties to the local community have the potential to help the student chapter, the college or university, and of course, the community ${ }^{10}$. A successful, visible community service project can favorably impact the regard in which the college or university and the civil engineering profession are held by the community ${ }^{11}$. University officials may also look more favorably upon your student group and be inclined to provide more financial support if you are improving the universities prestige in the community ${ }^{12}$. Future employers, clients and university officials would love to see your student chapter community service project featured in local newspapers. Contributing to the local community will make the college experience richer and more rewarding.

\section{Planning Community Service Projects}

Students should develop a general planning document that will guide the current project as well as having the potential to guide future community service projects ${ }^{13}$. Once completed, the planning document will tell future students exactly how to solicit, plan, fund, and successfully execute community service projects. The planning document should include:

1. Introduction

2. Community Service History

3. Objectives of the Community Service Project

4. Project Selection Criteria

5. Project Solicitation

6. Local Community Visits

7. Project Selection Process

8. $\quad$ Fundraising

9. Project Design Report

10. Construction Schedule

11. Aftermath

The entire process is shown schematically in Figure 1 where the community service project is divided into four phases: Project Selection, Design and Planning, Construction, and Final Details. Each of these report sections is briefly described below. 


\section{Phase I}

PROJECT SELECTION

(Summer and Fall)

Solicit candidate projects

Contact community leaders

Compile list

Visit and photograph sites

Estimate scope

Project Ranking

Project selection by students

Begin Fundraising

Phase II

DESIGN AND PLANNING

(Fall and Winter)

Interact with client

Schedule

Design

Permits

Fundraising and material procurement

Plan and solicit volunteers

\section{Phase III}

CONSTRUCTION

(Winter and Spring)

Appoint task and group leaders

Communicate the action plan

Coordinate volunteer activities Interact with client

Double check everything

Supervise and monitor

\section{Phase IV}

\section{PROJECT COMPLETION}

(Spring and Summer)

Ribbon cutting or dedication cere mony

Final project report

After action report

Repeat Process for Next Year

Figure 1. Phases of the Annual Community Service Project Cycle 


\section{Introduction and Community Service History}

The junior students within the Chapter have to be stimulated and motivated by some previous success in undertaking such a project. If the Chapter has had prior experience, a presentation of past projects is essential. This presentation needs to include the selection process, completed drawings, and pictures of the completed project. If the Chapter has had no prior experience, then it may want to contact other Student Chapters who have had such experience and invite them to give a presentation to your members to promote interest. This section of the planning document should briefly document, or at least list, those previous community service projects undertaken by your student chapter.

\section{Objectives of the Community Service Project}

After the introduction and a brief history of community service projects at your organization, one of the first leadership aspects of community service planning is to develop a list of objectives for completing a community service project. Describe exactly what you hope to accomplish. It does not matter if you think small or large, but it is imperative that you are honest with yourself in what you hope to accomplish with the project. Specific objectives might include those listed below:

- $\quad$ Applying engineering knowledge

- $\quad$ Working with your hands

- $\quad$ Building something (anything)

- $\quad$ Build something specific (e.g., a playground)

- Working on a real-world project

- Help someone who is truly needy

- Helping children or the elderly

- $\quad$ Helping a specific group

- $\quad$ Managing a complex project involving others

- Maximizing positive exposure and publicity

This list includes one item regarding publicity and exposure. A successfully completed project should bring positive exposure to your group. Thus, such considerations should not be considered negatively in your project selection criteria, as long as publicity is not the most important factor. Consideration of public exposure can often be used as a tiebreaker between otherwise equally ranked challenging, worthwhile projects. If a great deal of public exposure and visibility is expected on a given project, then the Chapter must be extremely careful to deliver what is expected.

\section{Project Selection Criteria}

With project objectives in hand, identify specific criteria for project selection. The criteria listed below should be considered. This is an extensive list of selection criteria; each Chapter should choose 5-6 of these criteria that are most important or relevant to its group and use those to help select viable projects. 
- $\quad$ There should be no potential conflicts of interest

- $\quad$ There should be a genuine need on the part of recipients

- $\quad$ An atmosphere of cooperation must exist between the recipients and the Chapter

- $\quad$ The project would not get done without you

- $\quad$ Recipient group should be nonprofit/ municipality

- $\quad$ Student interest and motivation should be high

- $\quad$ Students should benefit from the experience (technical, managerial, leadership, other)

- The probability of successful completion is high

- $\quad$ The site should be within a 1-hour drive (or less) from your central location

Each community service project must be professionally rewarding and allow the application of engineering knowledge. This does not always involve construction. In the past, Student Chapters have completed engineering reports based on feasibility studies and design recommendations for community groups.

One of the most important aspects of the community service is that of helping the needy in the community. Therefore, an evaluation should be made as to whether or not this project would be completed without the help of the Student Chapter. The enthusiasm of the recipient is very important; if there is not a definite desire for this project to proceed, then the likelihood of success is greatly diminished. Finally, look for an atmosphere of cooperation during meetings with the possible recipients; after all, this should be a friendly, cooperative venture. One such successful project was the design and construction of a $\$ 45,000$ playground and wheel-chair ramp for the New England Home for Little Wanderers, Knight Children's Center, in Boston, MA ${ }^{14}$. Photos from this project are shown in Figures 2, 3, 4, 5, and 6.

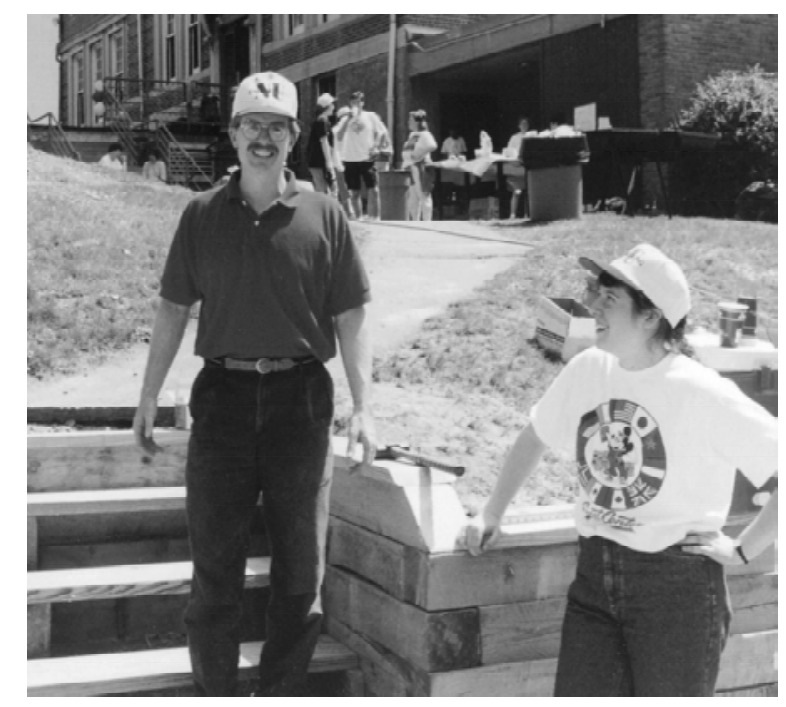

Figure 2. Taking a break after building timber walls and stairs around play area.

The feasibility of a project will depend on the individual Chapter. If this is the first community service project your chapter has tried, the scope should be well defined and limited to ensure its 
success. In addition, most projects should be planned to be completed in a school year - it is unlikely that fellow students will be willing or able to work during summer months, and the senior student leaders will typically have graduated.

Finally, the most important criterion: try to identify a project with a high student satisfaction coefficient. If a particular project does not excite student volunteers, it will take a student leader with extraordinary leadership abilities to hold the group together and successfully complete the project. Another project that is perceived as fun or enjoyable will be easier to manage, will reduce leadership challenges, and the probability of success will increase dramatically.

\section{Project Solicitation}

If a project has not already been identified, students will have to search for viable candidate projects. A solicitation letter should be developed describing who you are, what you hope to accomplish, and asking questions of candidate groups to determine if the candidates and potential projects meet your selection criteria and objectives. Generate a succinct questionnaire to distribute with your solicitation letter to concisely gather necessary information. Generate lists of potential clients from the phone book. Send out extra copies of your questionnaire or invite recipients to copy the questionnaire and distribute it to other candidate groups. You will be amazed at the high percentage of completed questionnaires returned, and will never have a shortage of candidate projects. The questionnaire should include the items listed below:

- What group are you?

- Whom do you represent?

- $\quad$ Are you a nonprofit group or a municipality?

- Who would benefit from the project?

- $\quad$ Please describe the project.

- $\quad$ Have you identified other groups willing to help in some way with this project?

- Is funding available or materials available?

- What is your time frame for completion?

Provide information for potential clients to contact your student leaders and faculty advisors. Finally, follow up all completed questionnaires with a letter or telephone call thanking each group for its participation and describing your time frame for project selection.

\section{Local Community Visits}

Visits to the local community can be done after solicitation letters have been mailed, or as part of the effort to develop a potential client list. Visit local community centers, schools, nonprofit clubs, camps, old-age homes, etc. to develop ideas for projects. Meet with local community leaders and representatives to help generate ideas and enthusiasm for the work you propose. It will also be necessary to visit specific project sites as you develop a short-list of candidate projects that seem initially to fit your objectives and selection criteria. Projects often look very different on site (some look better, some worse) than they appear on paper. Carefully evaluate commute options for student volunteers. Is the site on a bus or train line or is safe parking available for 
personal cars? Is the site in a relatively safe location so that student volunteers will feel comfortable enough to return to the site for another workday?

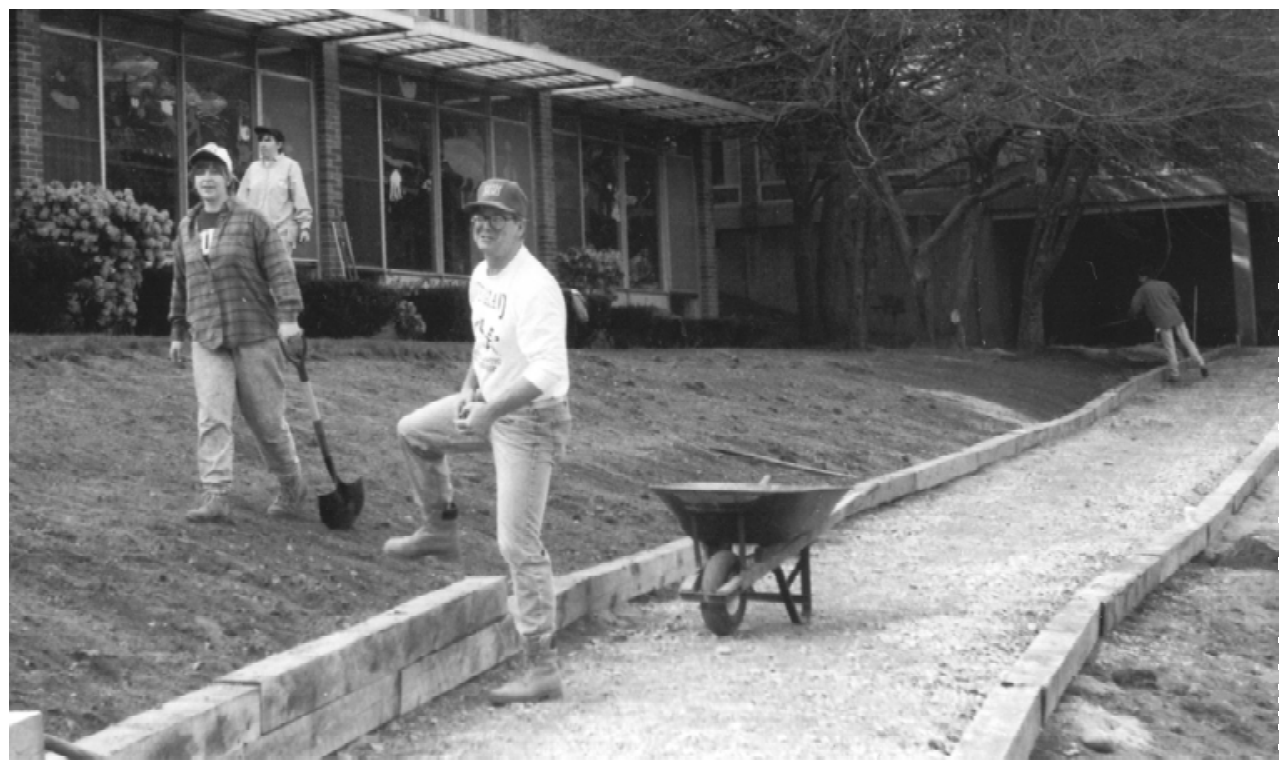

Figure 3. The wheel-chair ramp and slope grading are shaping up.

\section{Project Selection Process}

Once the Chapter has determined its objectives for completing a community service project, established the project selection criteria, and completed the project solicitation, it is time to select the best project for the Chapter. The project selection process is best described in two activities.

\section{Project Screening Matrix}

Students should develop a matrix with a numeric rating system for each of the project selection criteria. Each potential project is then rated separately on each of the criteria and an overall rating is calculated. For example, rank each of the criteria with the number 1-3; a higher number corresponds to a better project potential. After adding the points associated with each project, the project with the highest rating should correspond with being a better choice as your community service project. However, this rating system should be used as a guide and should not preclude the final selection of a lower ranking project.

The following criteria were chosen to evaluate and rate the solicited projects:
- $\quad$ Project complexity
- $\quad$ Proximity
- $\quad$ Student benefit
- $\quad$ Potential for publicity
- $\quad$ Available resources 
The rankings for each of these criteria are described below. You should use these only as a guide; feel free to modify the details of each ranking.

\section{Project complexity:}

- Difficult: Completion of the project is unexpected because the time involved to complete it is not feasible. Also, the project will require individual research on material not yet covered and students will be seriously challenged to find a solution to an academically complex problem.

- $\quad$ Medium: This type of project will either be academically challenging with a small time requirement to complete or will require large amounts of time to complete a non-complex problem.

- $\quad$ Easy: This type of project is best suited for the chapter because the concept is easy and will require very few weekends to complete.

\section{Proximity:}

- $\quad$ Far: Driving distance to site is greater than 45 minutes.

- $\quad$ Medium: Driving distance to site is within 20 to 45 minutes.

- $\quad$ Close: Driving distance to site is less than 20 minutes.

\section{Student Benefit:}

- $\quad$ Low: The project will be service oriented only and will not provide a challenging leadership or academic experience.

- $\quad$ Medium: The project will provide either a small academic challenge with numerous leadership challenges or small leadership opportunities with numerous academic challenges.

- High: This type of project provides both a challenging academic solution as well as challenging leadership experience.

\section{Public Relations:}

- Low: This sort of project is not visible to the community at large. The only people who can see it are those for whom the project was completed, and no recognition is brought to the project team or the university.

- $\quad$ Medium: This type of project is visible to the community for which it was done; however, it is not likely to receive any type of recognition.

- $\quad$ High: This type of project is one that is highly visible to the community and likely to receive significant recognition for the project team and the university. 


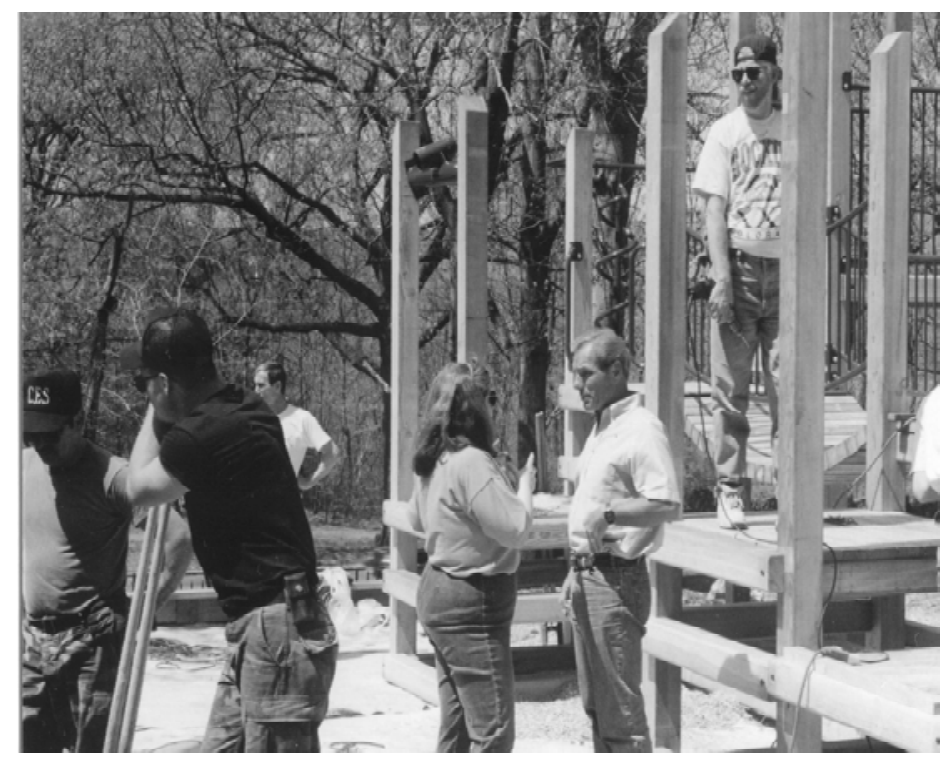

Figure 4. Planning and design are not complete until construction is over.

\section{Available Resources:}

- $\quad$ None: No materials or funds have been allocated for the project.

- $\quad$ Some: Some portion of materials, services, or funds have been allocated for the project.

- $\quad$ Yes: The beneficiaries have stated that they have all necessary resources for the project all they need are willing volunteers to plan and execute.

\section{Project Selection}

Once the matrix is completed, there should be 1 to 3 standout projects. At this point, students need to contact the potential beneficiaries to arrange an interview and a site tour. A list of specific questions regarding the project should be made prior to meeting with the beneficiary and several students should attend the meeting. Photographs or slides of the site should be taken to help develop design ideas or plans of action; provide visual information for the Chapter presentation; and provide photos for "before" and "after" sections of the Project Report. An initial estimation of what the project will need for completion should also be made at this time. These needs include personnel, equipment, necessary design work, and necessary construction work.

Now, it is time to make the project presentations to the Chapter. This Chapter meeting should be well advertised so that there is a good representation of the members present to vote for the Chapter's community service project. If the members are to work on a project, they need to be given the chance to choose. The students involved in the interviewing process for the top projects should give a brief presentation at a Chapter meeting and be prepared to answer questions from the Chapter members. Photos taken of the site, slides, plans and sketches should all be used to convey the nature and scope of the project to the members. A list of the pros and cons for each 
project should be developed as a result of the presentations. Finally, a group vote should be held to choose the community service project.

\section{Fundraising}

If materials and or funding have not already been identified, they will have to be solicited by the student group. Another solicitation letter should be developed describing who you are, what you hope to accomplish, and asking whether potential donors would be willing to donate expertise, materials, equipment, labor, or money for the completion of a community service project.

Generate lists of potential donors from the phone book, engineering organizations, contractors, material suppliers, etc. For this activity, you may be amazed at the low percentage of completed questionnaires returned. Effective fundraising usually requires a more personal approach, particularly with regard to contractors and material suppliers. If a project has been selected, describe it to potential donors. Benefits to potential donors are noted below and should be stress to potential donors in letters or phone calls:

- $\quad$ The benefit they will provide to the local community

- $\quad$ The positive publicity and good-will they will receive for their help

- $\quad$ The tax benefit

- The opportunity to work with students and attract the best students for future employment

The bottom line is that it will cost donors something for their help regardless of any benefit. Appeal gently to their philanthropic side. Also, if Contractor A agrees to donate a backhoe for a few days, tell Contractor B; he will be more highly motivated to help if he knows his competitors are involved. Finally, spread the load. Do not expect any one group to donate everything. Look for lots of limited participation from lots of different sources.

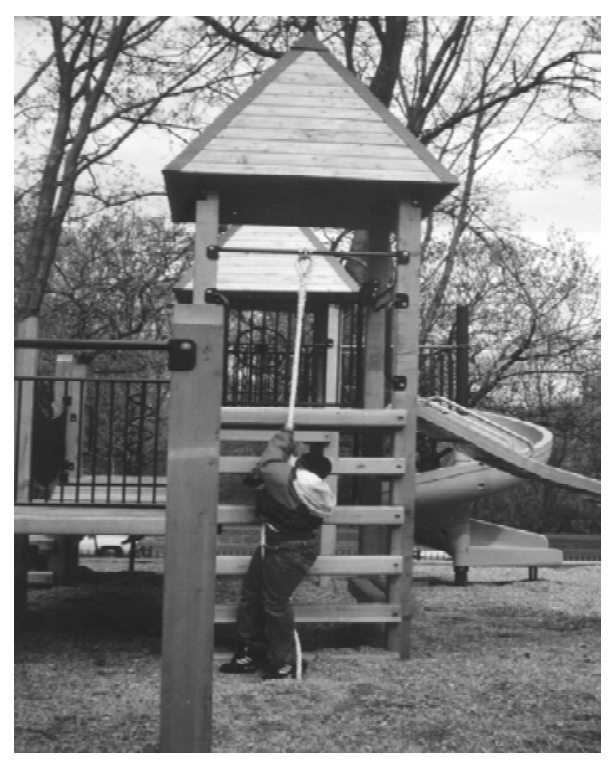

Figure 5. New England Home resident tries out the new playground in his backyard. 


\title{
Project Design Report and Schedule
}

The planning document should include a brief design report for an example project. This will be a real engineering report in every aspect and should include the specifics noted in the list below:

$\begin{array}{ll}\text { - } & \text { Project description } \\ \text { - } & \text { Utility locations } \\ \text { - } & \text { Zoning issues } \\ \text { - } & \text { Permits required } \\ \text { - } & \text { Design drawings and calculations } \\ \text { - } & \text { List of materials required } \\ \text { - } & \text { Schedule } \\ \text { - } & \text { Execution Details } \\ \text { - } & \text { Personnel involved } \\ \text { - } & \text { Other pertinent information }\end{array}$

Develop a working schedule for future community service projects from solicitation through final construction and dedication. The schedule should include all real limitations such as summer vacation periods, other vacations, holiday weekends, exam periods, and seasonal weather for your area that may preclude outdoor construction. Your schedule should allow sufficient time, at a minimum, for the project components listed below:
- $\quad$ Project selection
- $\quad$ Planning and financing
- $\quad$ Design and permitting
- Material procurement
- Construction
- $\quad$ Report

The final project report should be a stand-alone design report that describes all aspects of the community service project from start to finish.

\begin{abstract}
Aftermath
No project is complete until it is placed into service; this is just as true for a playground as for a wastewater treatment plant. Allow time in your schedule to arrange a dedication or ribbon cutting ceremony. Remember to thank and invite to the ceremonies any donors and contributors. Until project dedication, the community service project is just another engineering project requiring your leadership, managerial skills, and intellectual ability.
\end{abstract}




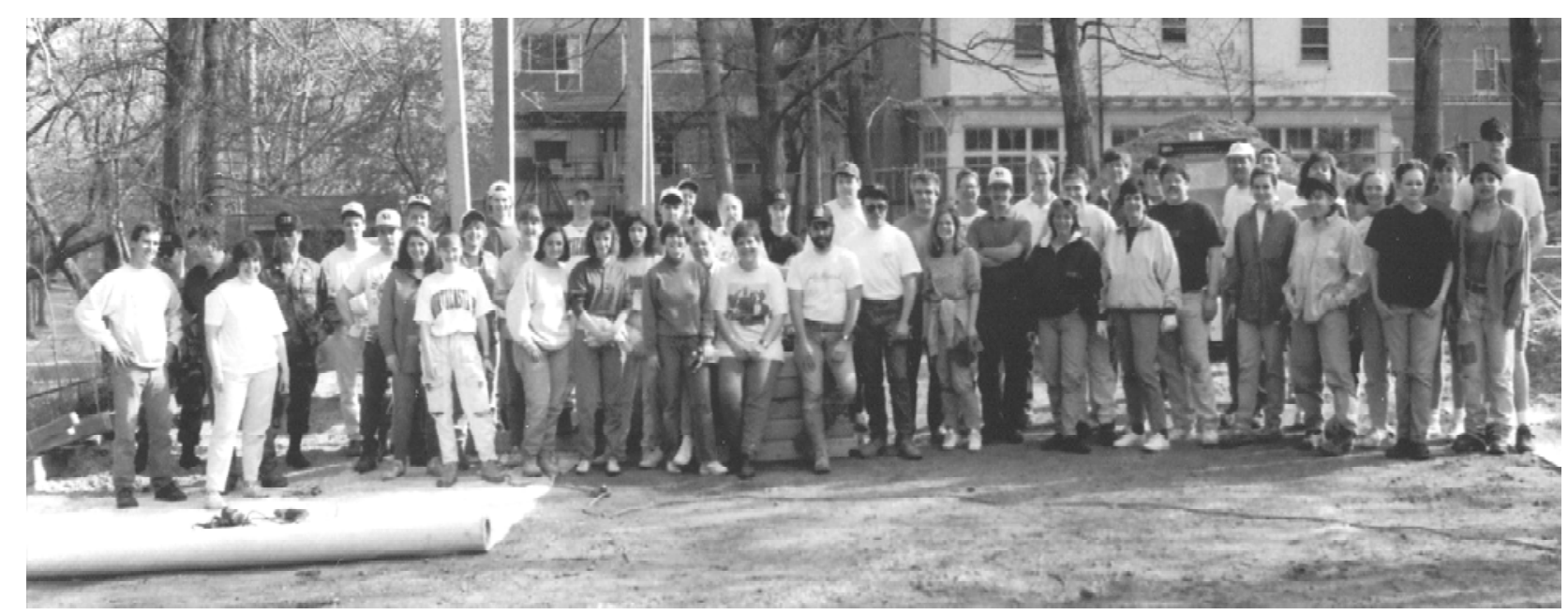

Figure 6. Chapter members and friends pause at the end of a long construction workday.

\section{Conclusions}

As former students and participants in community service projects, the experience we received from working with our fellow students and seeing an idea come to fruition through the work of our blistered hands is immeasurable. We shared and still share an incredible pride with our fellow students and have memories that supersede any academic achievements. This is the ultimate benefit of community service for student chapters-- the opportunity to use your professional knowledge and skills to improve the lives of others!

\section{References}

1. Degyansky, Milan E., "The Role of Student Clubs within ASCE”, Conference Proceedings, Education and Continuing Development for the Civil Engineer: Setting the Agenda for the 90's and Beyond, ASCE, Las Vegas, NV, April 1990.

2. Ghafoori, Nader and DeNatale, Jay S., "ASCE's Student Chapters: Statistical Analyses of Key Characteristics", Journal of Professional Issues in Engineering Education and Practice, Vol. 117, No. 3, July 1991, p. 267-274.

3. ASCE, Student Group Handbook, Guidelines for Student Officers, Faculty Advisors, Contact Members, 1992.

4. Evans, Mark D., Evans, Denise M., and Sherman, Lisa D., "Seven Keys to a Successful ASCE Student Chapter or Club--A Guide For Student Leaders And Faculty Advisors," accepted for publication to the Journal of Professional Issues in Engineering Education and Practice, ASCE, 2000.

5. Henkel, Kenneth; Mow, Maurice; and Anderson, Edward, "Factors for a Successful ASCE Student Chapter", Conference Proceeding, part of Civil Engineering Education, George k. Wadlin, ed., 1984.

6. Bennis, Warren G., On Becoming A Leader, Perseus Press, 2nd Edition, August 1994

7. Beder, Sharon, "Beyond Technicalities: Expanding Engineering Thinking", Journal of Professional Issues in Engineering Education and Practice, ASCE, Vol. 125, no. 1, January 1999.

\footnotetext{
"Proceedings of the 2003 American Society for Engineering Education Annual Conference \& Exposition Copyright (C) 2003, American Society for Engineering Education"
} 
8. Bowman, Bruce A. and Farr, John V., "Embedding Leadership in Civil Engineering Education", Journal of Professional Issues in Engineering Education and Practice, ASCE, Vol. 126, no. 1, January 2000.

9. McCuen, Richard H., “A Course on Engineering Leadership”, Journal of Professional Issues in Engineering Education and Practice, ASCE, Vol. 125, no. 3, July 1999.

10. ASCE News, "Four Student Chapters Clean up Their Communities- and Get Rewarded", Vol. 24, No. 10, October 1999, pg. 7.

11. Shah, Kanti L., "Benefits of an Active ASCE Chapter to an Undergraduate Engineering College", Conference Proceedings, Education and Continuing Development for the Civil Engineer: Setting the Agenda for the 90's and Beyond, ASCE, Las Vegas, NV, April 1990.

12. DeNatale, Jay S. and Ghafoori, Nader, Relation Between Institutional Support and Student Chapter Achievement", Journal of Professional Issues in Engineering Education and Practice, ASCE, Vol. 117, no. 3, July 1991.

13. Gray, Charles; Miller, Mickey; and Evans, Mark D., "Community Service Project Planning Report", volume I, The US Military Academy, West Point, NY, 1997.

14. Northeastern University ASCE Student Chapter, "New England Home for Little Wanderers, Knight Children's Center, Playground and Site Improvements", Community Service Project Final Report, Boston, MA 1994.

\section{Biographical Information}

\section{MARK D. EVANS}

Dr. Mark D. Evans is an Associate Professor and Deputy Director of the Civil Engineering Division at United States Military Academy (USMA). He is also an associate editor of the ASCE Journal of Professional Issues in Engineering Education and Practice. His web page is available at: http://www.dean.usma.edu/cme/faculty/evans.htm

\section{DENISE M. EVANS}

Denise Evans is a civil and industrial who teaches math and physics at Washingtonville High School, Washingtonville, NY. 